
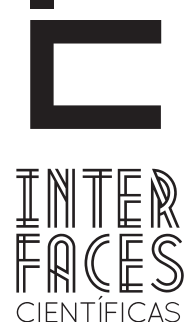

EDUCAÇÃO

\title{
AVA UNIASSELVI: UM OLHAR SOBRE O NÍVEL DE INTERAÇÃO DO ALUNADO JUNTO ÀS TRILHAS DE APRENDIZAGEM
}

André Luiz Alves ${ }^{1}$

\section{RESUMO}

Tendo como enfoque a ideia de que o computador - conectado à Internet, mudou o modo de ensinar e aprender; este artigo propõe refletir sobre as interações entre aprendentes do sistema de Educação a Distância do Centro Universitário Leonardo da Vinci - UNIASSELVI (SC), no Polo Paulo Afonso-Ba, através das "Trilhas de Aprendizagem" do Ambiente Virtual de Aprendizagem (AVA), no processo de ensino-aprendizagem. Considerando a necessidade de se investigar a construção do conhecimento nestes espaços virtuais, a pesquisa tem abordagens teórico-metodológicas de cunho quanti-qualitativa, com aplicação de questionários semi-estruturados contendo questões objetivas e subjetivas e
Maria do Socorro Pereira de Almeida²

os resultados obtidos apontam o nível de interação do alunado junto aos recursos e as ferramentas pedagógicas e tecnológicas do AVA. Busca-se embasamento bibliográfico através de estudiosos da educação em geral e de especialistas em EAD. Assim, pesquisaram-se vários artigos, dissertações, livros, revistas e teses para que pudéssemos aprofundar nosso conhecimento e dar melhor qualidade ao estudo.

\section{PALAVRAS-CHAVE}

Educação a Distância. Ambiente Virtual de Aprendizagem. Interações. 


\section{ABSTRACT}

Having as focus the idea that the computer - connected to the Internet has changed the way of teaching and learning, this paper proposes to reflect on the interactions between learners system of Distance Education of the Centro Universitário Leonardo da Vinci - UNIASSELVI (SC), in Paulo Afonso-Ba campus, through the "Learning Tracks" the Virtual Learning Environment (VLE), in the process of teaching and learning. Considering the need to investigate the construction of knowledge in these virtual spaces, research has theoretical and methodological approaches of quantitative and qualitative nature, with the application of semi-structured questionnaires containing objective and subjective questions and the results obtained indicate the level of interaction of the students with resources and pedagogical and technological tools of the VLE. Seeks to bibliographic foundation through education scholars in general and experts in Distance Education. Thus, searched many articles, dissertations, books, journals and theses for us to deepen our knowledge and give best quality to the study.

\section{KEYWORDS}

Distance Education. Virtual Learning Environment. Interactions.

\section{INTRODUÇÃO}

Atualmente, quando se fala em Educação a Distância, se pensa em Internet. Nessa tendência de vanguarda do ensino superior, a EAD é uma realidade crescente na sociedade vigente, ou seja, é grande a procura por cursos on-line para satisfazer as amplas e diversificadas necessidades de qualificação existentes, uma vez que, o próprio mercado de trabalho, cada vez mais exigente e excludente, se encarrega de desfazer as resistências.

\section{RESUMEN}

Teniendo como foco la idea de que la computadora - conectada a la Internet ha cambiado la forma de enseñar y aprender, en este trabajo se propone reflexionar sobre las interacciones entre los alumnos del sistema de Educación a Distancia del Centro Universitário Leonardo da Vinci - UNIASSELVI (SC), en el Polo Paulo Afonso-Ba a través de las "Rutas de Aprendizaje" del Ambiente Virtual de Aprendizaje (AVA), en el proceso de enseñanza y aprendizaje. Teniendo en cuenta la necesidad de investigar la construcción del conocimiento en estos espacios virtuales, la investigación tiene enfoques teóricos y metodológicos de naturaleza cuantitativa y cualitativa, con la aplicación de cuestionarios semi-estructurados con preguntas objetivas y subjetivas los resultados obtenidos indican el nivel de interacción de los estudiantes junto a los recursos y a las herramientas pedagógicas y tecnológicas del AVA. Se busca una base bibliográfica a través de especialistas en educación en general y expertos en EAD. De esta manera se han investigado diversos artículos, disertaciones, libros, revistas y tesis con la finalidad de profundizar nuestro conocimiento y darle una mejor calidad al estudio.

\section{PALABRAS CLAVE}

Educación a Distancia. Ambiente Virtual de Aprendizaje. Interacciones.

Prova disso, segundo as estatísticas da Associação Brasileira de Educação a Distância (ABED), disponibilizadas no Anuário Brasileiro Estatístico de Educação Aberta e a Distância de 2008, é que um em cada cinco jovens faz parte desta diferente sala de aula; onde a inserção de novos recursos e ferramentas tecnológicas já não são mais novidade. 
Como é sabido, a revolução no modo de ensinar e aprender sempre foi um fato e na última década, com o possível acesso à tecnologia de informação e ao mundo virtual, essas transformações se tornaram mais intensas e mais rápidas. Contudo, o ensino na era das TIC's - Tecnologias de Informação e Comunicação utiliza um arsenal de mídias, isoladas ou combinadas, além de outros materiais de apoio, que vêm colaborar com o acesso e disseminação do conhecimento nos mais diversos "ambientes de aprendizagem".

Portanto, ao provocar uma quebra do paradigma educacional, esses pacotes informatizados exploram todo o potencial de interação que a plataforma de ensino-aprendizagem, mais flexível, permite, além de outras vantagens. Uma delas seria o fato de que o aprendente pode conciliar o tempo do trabalho com o do estudo, sem que haja um choque.

Nesse pensar, o Ambiente Virtual de Aprendizagem (AVA), da UNIASSELVI, coloca à disposição dos alunos "Trilhas de Aprendizagem" em cada uma das disciplinas e de seus respectivos cursos, com o intuito de promover a interação com o conteúdo do Caderno de Estudos e com os encontros presenciais (aulas uma vez por semana).

Diante disso, o presente artigo tem a pretensão de refletir como os aprendentes deste intercâmbio de saberes, mediado por modernas e avançadas tecnolo- gias, interagem com propostas pedagógicas inovadoras, priorizando a qualidade do processo de ensino e aprendizagem - destacados nestas salas virtuais.

Ademais, a pesquisa bibliográfica a respeito do tema proposto, versará sobre a Educação a Distância - sem a intenção de acompanhar o seu crescimento histórico, e sim, perceber e legitimar sua prática, através do Polo usado como corpus para o estudo. No entanto, buscamos embasar as ideias propostas, amparadas por pesquisadores da área como Palloff e Pratt (2004), Maia e Mattar (2007), Moore e Kearsley (2008) entre outros.

Em seguida, serão apresentadas as possibilidades e potencialidades do AVA UNIASSELVI e, por fim, serão apontados os resultados e discussão da pesquisa, por meio de questionários, aplicados aos estudantes de cursos distintos que compreendem a modalidade EAD, da UNIASSELVI, no Polo Paulo Afonso-Ba.

Ressalta-se que esse estudo tem sua relevância, primeiro por trazer à tona, não o sistema em si, mas os aprendentes e as relações e percepções deles entre si e com as ferramentas oferecidas; e depois, por proporcionar uma nova forma de perceber os estudos desta modalidade de ensino, que possibilita a autoaprendizagem - com a mediação da tecnologia, e como se processam as interações no AVA, trazendo para discussão, também, a figura do professor-tutor.

\section{PROCEDIMENTOS METODOLÓGICOS}

O AVA é um espaço virtual dinâmico, intuitivo e interativo no processo de ensinar e aprender, na EAD, da UNIASSELVI. Com abordagens teórico-metodológicas de cunho quanti-qualitativa, a pesquisa que serve de base para este estudo foi realizada entre os meses de junho e julho de 2012, com o intuito de analisar o nível de interação do alunado junto aos recursos e fer- ramentas pedagógicas e tecnológicas, através desta plataforma, no Polo Paulo Afonso-Ba.

A partir da literatura estudada e dos objetivos desta pesquisa, foi elaborado um questionário semi-estruturado contendo 11 (onze) questões objetivas e 3 (três) subjetivas que, de acordo com Lakatos e 
Marconi (2001, p. 201): “é um instrumento de coleta de dados, constituído por uma série ordenada de perguntas, que devem ser respondidas por escrito e sem presença do entrevistador”. Foram aplicados 165 questionários com alunos de diferentes cursos desta sala virtual.

Após a aplicação do questionário, foram coletados os dados e expostos em forma de gráficos que "podem evidenciar aspectos visuais dos dados, de forma clara e de fácil compreensão" (LAKATOS; MARCONI, 2001, p. 170) e, em seguida, realizada a análise dos resultados obtidos através deste instrumento.

Além da escalada vertiginosa que este sistema de ensino apresenta no mundo todo, inclusive no Brasil, procurou-se embasamento bibliográfico através de estudiosos da educação em geral e de especialistas em EAD, que vem tornar a análise abrangente, como também, contribuir para validação desta pesquisa. Assim, pesquisaram-se vários artigos, dissertações, livros, revistas e teses para que pudéssemos aprofundar nosso conhecimento e dar melhor qualidade ao estudo.

Este trabalho, contudo, não anseia apresentar um ponto de vista final sobre este recorte, mas representará um marco relativo ao estudo desta modalidade de ensino que possibilita a autoaprendizagem, com a mediação da tecnologia, além de assumir um papel importante na sociedade vigente. Em suma, pretende-se, divulgar os resultados desta pesquisa em eventos científicos, publicações impressas e eletrônicas objetivando compartilhar o conhecimento adquirido.

\section{A EDUCACÃ̃O A DISTÂNCIA}

A Educação a Distância ou EAD, como ficou conhecida, é uma modalidade de ensino que se caracteriza, principalmente, pela separação (tempo e espaço) entre aquele que ensina e aquele que aprende, é ainda muito recente, mas já possui um público considerável no país e corresponde aos avanços da tecnologia rapidamente. Foi instituída no Brasil através da Lei de Diretrizes e Bases da Educação Nacional (Lei no 9.394, de 20 de dezembro de 1996), mas só a partir de 2005 , sob novas regulamentações, ganhou aval como forte componente da política educacional - deixando de ser entendida como "emergencial”, por exercer um importante papel no processo de ensino e aprendizagem.

Não tão recente quanto parece, nas entrelinhas do Módulo da Disciplina Educação a Distância e Métodos de Autoaprendizado, da UNIASSELVI (2009, p. 12), alguns autores afirmam que o advento da Educação a Distância se dá em virtude da invenção da escrita - que possibilita a comunicação entre pessoas e a do- cumentação de informações, obras e registros; outros defendem que a EAD tornou-se possível apenas em razão da invenção da imprensa (século $X V$ ), que permitiu maior acesso à informação, facilitou o processo de divulgação de ideias, democratizou o conhecimento, potencializou reformas e revoluções.

Já do ponto de vista da tecnologia utilizada, a Educação a Distância se desdobra em gerações que ampliaram ainda mais o alcance e as possibilidades interativas, e de sucesso, desta modalidade de ensino. Corroborando essas definições, Moore e Kearsley (2008, p. 25), afirmam: 
de interação de um grupo em tempo real a distância, em cursos por áudio e videoconferência transmitidos por telefone, satélite, cabo e redes de computadores. Por fim, a geração mais recente de educação a distância envolve ensino e aprendizado on-line, em classes e universidades virtuais, baseadas em tecnologias da internet.

Diante dessas características abordadas pelos autores, nota-se que as gerações em EAD não ilustram simplesmente um conceito de evolução tecnológica, afinal, essa diversidade de tecnologias dão suporte à representação e distribuição de conteúdos e a comunicação nestas redes onde o ensino e aprendizagem acontecem.

Em tempo de menos deslocamentos e mais interação, e diante de um cenário marcado pela mediação das TIC's - incorporadas na rotina de aprendizagem, a sensação de separação geográfica entre docentes e alunos desaparece através dos estudos midiatizados. Nesse contexto, Maia e Mattar (2007, p. 6) asseguram que:

O estudo a distância implica, portanto, não apenas a distância física, mas também a possibilidade da comunicação diferida, na qual o aprendizado se dá sem que, no mesmo instante, os personagens envolvidos estejam participando das atividades, ao contrário do que ocorre normalmente no ensino tradicional e presencial.

Sendo assim, é preciso muita disciplina e concentração por parte dos alunos que optam por um estudo não totalmente virtual. Além de ter um perfil dinâmico, este formato exige que o estudante também tenha uma postura autodidata - ao estabelecer ritmos de estudo diferenciados, sendo batizados ainda segundo os autores (2007, p. 85), de "aprendiz virtual", isto é, um aprendiz independente e disposto à autoaprendizagem.

Ao completar esse contexto e levando em consideração a autonomia deste acadêmico, Moore e Kearsley (2008, p. 187), afirmam que "os alunos que planejam seu tempo de estudo e estabelecem horários para concluir o curso têm maior possibilidade de obter sucesso na educação a distância". Como reflexo disso, segundo o Anuário Brasileiro Estatístico de Educação Aberta e a Distância (2008, p. 17), a maior nota divulgada pelo Exame Nacional de Avaliação do Desenvolvimento do Estudante (ENADE/2006) é de um aluno de EAD, no entanto, os resultados são sempre animadores e convincentes e levam a crer que "educação a distância não é uma opção, é o futuro" (Revista Ensino Superior, p. 24).

Conectada a esta realidade, pesquisa divulgada em 09/08/2011 pelo Comitê Gestor da Internet no Brasil (CGI.br) revela que $64 \%$ dos professores entrevistados acreditam que os alunos entendem mais de computador e internet do que eles próprios. E é nesse âmbito que, assim como o aluno, o professor de EAD precisa adotar novas posturas diante do processo de ensino-aprendizagem, tendo em vista que este universo possui uma estrutura diferenciada.

Sendo assim, o nível de interação e a qualidade desses cursos tendem a melhorar cada vez mais como observam Palloff e Pratt (2004, p.141), quando alegam que:

[...] cursos com altos níveis de interação tendem a obter maior índice de satisfação e menor índice de abandono. Assim, incentivar um alto nível de interação é papel fundamental do professor. Na verdade, talvez seja a sua tarefa mais importante no ambiente de aprendizagem on-line.

Dessa forma, no modelo de Educação a Distância proposto pela UNIASSELVI, de um lado, o professor docente é responsável por pensar e planejar a disciplina como autor do material didático e arquiteto do curso, além de acompanhá-la virtualmente; de outro, o tutor faz a mediação entre o professor e o aluno - que assegura o entendimento do estudante por parte do conteúdo durante os encontros presenciais, ao criar possibilidades e condições para que o aluno construa seu próprio conhecimento. Isso mostra que a EAD não se baseia em uma só pessoa, mas numa equipe. 


\section{AVA UNIASSELVI: UMA SALA DE AULA DIFERENTE}

A Educação a Distância vive um momento de crescimento e organização, nas várias metodologias existentes (síncronas ou assíncronas) ${ }^{1}$, acadêmicas e corporativas, uma vez que, através da conexão tecnológica é possível que as aulas cheguem onde o aluno está - superando limites de tempo e espaço entre ensinantes e aprendentes.

Nesse sentido, o AVA UNIASSELVI é a página pessoal do aluno, é a sala de aula dele, onde, ao acessar, login (número de matrícula) e senha são solicitados para autenticação de acesso. Como já foi destacada anteriormente, esta plataforma virtual de aprendizagem colaborativa está pautada em "Trilhas de Aprendizagem" e estruturada com várias interfaces de informação, comunicação e de conteúdo; capazes de promover uma aprendizagem contínua, significativa e autônoma - conforme consta no 'Manual do AVA UNIASSELVI', a saber:

A "Trilha da Disciplina" é um caminho virtual regido por uma breve contextualização sobre o conteúdo estudado na disciplina, também poderá conter dicas de estudo e lembretes das atividades a serem desenvolvidas. Após a contextualização, são potencializados em cada etapa, os recursos pedagógicos relacionados à especificidade dessas, como: Plano de Ensino; Caderno de Estudos Virtual; Vídeo da Disciplina; Material de Apoio; Fórum; Enquete; Objeto de Aprendizagem e Curso de Nivelamento.

Já a "Trilha do Curso", possibilita aos acadêmicos da UNIASSELVI se inteirarem sobre o Projeto Pedagógico do Curso; os Princípios Norteadores da Instituição; o Vídeo de boas-vindas da Coordenação; a Dinâmica dos Encontros Presenciais; os Critérios de Promoção das Avaliações e a Avaliação do Curso; informações sobre as Práticas Educativas; as Atividades

1 Síncrona - comunicação em tempo real. Assíncrona - comunicação on-line a qualquer tempo.
Complementares; os Estágios Curriculares Supervisionados e o Trabalho de Graduação. Dessa maneira, percebe-se que a UNIASELVI se preocupa em manter seu discente bem informado, trata de diminuir, ao máximo, as interrogações que possam ocorrer por parte dele.

Da impressão tradicional ao digital, fornecer um material didático agradável, com excelência em usabilidade e design instrucional, além de outros referenciais de qualidade; são condições necessárias, mas não suficientes para garantir uma aprendizagem efetiva. Por essas razões, (PEREIRA; SCHIMITT; DIAS, 2007, p. 4.) ressaltam que:

\begin{abstract}
A qualidade do processo educativo depende do envolvimento do aprendiz, da proposta pedagógica, dos materiais veiculados, da estrutura e qualidade de professores, tutores, monitores e equipe técnica, assim como das ferramentas e recursos tecnológicos utilizados no ambiente.
\end{abstract}

A partir do exposto, vê-se que não é o curso em si, mas a qualidade dele que faz a diferença, ou seja, a competência e a eficiência da equipe do Núcleo de Educação a Distância (NEAD) - órgão responsável pela coordenação administrativa e didático-pedagógica é de vital importância. No entanto, o aluno deve fazer a sua parte da melhor maneira possível, com dedicação e comprometimento, para que o aprendizado ocorra e o direcionamento para a construção do conhecimento seja realmente eficaz.

Podemos ainda acrescentar que, nos cursos EAD da UNIASSELVI, a interação humano-computador ocorre por meio das "Trilhas de Aprendizagem", onde o diálogo interdisciplinar entre os partícipes contempla a ação mediadora do professor-tutor, no processo de ensino e aprendizagem, sendo favorecido por um conjunto de recursos e ferramentas tecnológicas; além de proporcionar um avanço na construção de novos conhecimentos. Assim, de forma sucinta, Kensky 
(2003), destaca que "o professor na sala de aula presencial tem o poder da 'fala', enquanto que no espaço virtual essa 'fala' é substituída pelo diálogo e colaboração entre os membros do grupo".

\section{INTERACÕES NO AVA: RESULTADOS E DISCUSSÃO}

Um dos mecanismos excelentes de interação e colaboração entre ensinantes e aprendentes é o Ambiente Virtual de Aprendizagem. Nesta sala de aula virtual, o aluno encontra vários instrumentos pedagógicos e tecnológicos que o auxiliam em seus estudos.

Com os aprendentes da UNIASSELVI, Polo Paulo Afonso-Ba, utilizou-se para a pesquisa um questionário semi-estruturado contendo 11 (onze) questões objetivas e 3 (três) subjetivas. Realizada entre os meses de junho e julho de 2012, participaram da pesquisa 165 alunos dos cursos de Administração, Ciências Biológicas, Ciências Contábeis, Gestão Ambiental, História, Letras, Pedagogia e Segurança no Trabalho - do $1^{\circ}$ ao $4^{\circ}$ períodos, do semestre letivo 2012/1.

A partir das informações e dados coletados nos questionários para retratar o nível de interação do alunado junto aos recursos e ferramentas pedagógicas e tecnológicas, desta plataforma de ensino-aprendizagem, observou-se que $53 \%$ dos estudantes acessam o AVA '1 vez por semana', enquanto $32 \%$ acessam ' 1 vez por dia', $14 \%$ 'mais de 2 vezes por dia' e $1 \%$ 'não acessa'. É interessante observar, no entanto, que para ter êxito nos estudos na modalidade à distância, é necessário acessar o AVA regularmente, pois esta ferramenta possibilita a construção de novos saberes. Se a troca de informações, disponibilidades de conteúdos e apreciação do assunto são feitas virtualmente, fica evidente que o aprendiz que não acessa frequentemente o AVA não terá o mesmo rendimento dos outros, uma vez que, o principal objetivo dessa modalidade de aprendizagem é justamente aproximar
Nessa perspectiva, passamos a parte prática da pesquisa em que demonstramos os dados colhidos através dos questionários já mencionados e a análise de dados para as considerações conclusivas do nosso estudo.

o estudante do conhecimento, usando a virtualidade, como sugere a condição do curso de EAD.

Vale ressaltar que o professor-tutor fornece instruções de utilização e exploração das ferramentas desse ambiente, as quais, $70 \%$ dos entrevistados consideram 'muito claras', 22\% 'pouco claras' e $8 \%$ 'nada claras'. Então, é importante frisar também que o 'Manual do AVA' encontra-se disponível para download na página pessoal do aluno. Contudo, é fundamental que o aluno se detenha à leitura, haja vista ser essa uma das principais ferramentas do curso.

Diferente do modelo tradicional, esta proposta tem a informática como aliada, de forma que o processo de ensino-aprendizagem pode funcionar em qualquer lugar e em qualquer horário - desde que o acesso a Internet seja assegurado. Sendo assim, quando questionados sobre o local onde mais acessa o AVA, $57 \%$ responderam que acessam em 'casa', $22 \%$ no 'trabalho', 12\% em 'Lan House' e 9\% nos 'Laboratórios do Polo'.

Deve-se considerar que, embora em alguns locais de trabalho se tenha essa possibilidade, a nosso ver, esses não são os locais ideais para esse tipo de acesso, pois se trata de um momento em que o aprendente deve estar concentrado e disponível para dar atenção total ao que está sendo estudado. Sendo assim, seria ideal que o estudante gerenciasse o seu tempo de estudo, como também, mantivesse um determinado local no seu convívio diário para um melhor aproveitamento do curso. 
Outro fator importante a ser observado é que, apesar de estimular a familiarização através do uso das TIC's, existem entraves a serem transpostos pelo estudante, como 'falta de tempo' (37\%), 'não tenho internet em casa' (21\%), 'conexão lenta' (14\%), 'falta de familiaridade com computadores' (3\%); para cumprir as etapas previstas no curso. Já $24 \%$ dos entrevistados responderam não encontrar 'nenhuma' dificuldade para acessar o AVA. Nesse contexto, diante das dificuldades apresentadas, vê-se a importância da visita aos 'Laboratórios do Polo' para uma melhor possibilidade de interação com o AVA, pois estes estão devidamente equipados para dar o suporte indispensável a quem deles necessita.

Para verificar o nível de interação com as "Trilhas de Aprendizagem" disponíveis no AVA UNIASSELVI, ocorrido em cada uma das disciplinas e de seus respectivos cursos, solicitou-se aos estudantes que apontassem os recursos pedagógicos mais utilizados por eles, constatando-se que $24 \%$ acessam o 'DVD da Disciplina', 21\% o 'Caderno de Estudos Virtual', 19\% realizam 'Curso de Nivelamento', 14\% aprofundam o conteúdo da disciplina ao acessar o 'Material de Apoio', 9\% participam dos momentos de discussão da ferramenta 'Fórum', 7\% acessam o 'Objeto de Aprendizagem' e 6\% interagem com a ferramenta 'Enquete' formando opiniões.

Como pôde ser visto, os percentuais de interação com as ferramentas Fórum (9\%) e Enquete (6\%), são considerados baixos, uma vez que, ao serem questionados sobre ter encontrado alguma dificuldade quanto a sua utilização; $35 \%$ responderam que 'desconhece a ferramenta' Fórum, enquanto $40 \%$ 'desconhece a ferramenta' Enquete.

Percebe-se um grau de interatividade favorável entre os estudantes, com alguns dos recursos e ferramentas pedagógicas desta modalidade, mas ainda é preciso estimular a participação deste aprendiz em outros "caminhos virtuais" de aprendizagem, de maneira a garantir uma trajetória acadêmica de sucesso.
Um dos objetivos do AVA é fornecer ferramentas que auxiliem o processo de ensino-aprendizagem de forma contínua, interativa e qualitativa. Entrando em contradição com as questões cinco e sete, no tocante à utilização do Fórum, constatou-se que 15\% julgam ser uma 'excelente' ferramenta para 'tirar dúvidas', $44 \%$ responderam ser um 'bom' canal para 'troca de ideias' durante os momentos de discussões. Apenas $1 \%$ dos entrevistados acha 'ruim' a 'rapidez na comunicação' e 16\% considera 'regular' a 'flexibilidade no tempo e no espaço'. O resultado apontou o quanto a ferramenta Fórum oportuniza uma maior solidez teórica sobre os temas abordados e que estão em discussão naquele momento do curso.

Posteriormente, ao serem indagados se as atividades realizadas no AVA contribuem para o aprendizado, $73 \%$ afirmaram que 'sim, pois os recursos tecnológicos oferecidos no AVA ampliam as possibilidades de ensino e aprendizagem', $21 \%$ responderam 'não, pois só consigo aprender com o professor-tutor durante os encontros presenciais' e $6 \%$ disseram 'nunca acessei o AVA'.

Além das conexões tecnológicas, no processo de ensino-aprendizagem, o que surpreende, positivamente, é que as respostas dos aprendentes do curso desenvolvido em AVA demonstram o quanto é importante a mediação do professor-tutor, pois é ele quem orienta o aluno nesses espaços virtuais, dando significado aos conteúdos.

\begin{abstract}
Cabe ao professor-tutor mediar todo o desenvolvimento do curso. É ele que responde a todas as dúvidas apresentadas pelos estudantes, no que diz respeito ao conteúdo da disciplina oferecida. A ele cabe também mediar a participação dos estudantes nos chats, estimulá-los a participar e a cumprir suas tarefas, e avaliar a participação de cada um. (GONZALEZ, 2005, p. 40)
\end{abstract}

No entanto, é interessante salientar que não tem sentido se fazer um curso a distância se a ferramenta, pela qual ele é proposto não é utilizada, como é o caso dos $6 \%$ que responderam 'nunca acessei o AVA'. 
Percebe-se, mesmo sendo o caso de uma minoria, que se faz necessário uma conscientização quanto à importância do uso da ferramenta para que o aprendente obtenha um bom desempenho.

Quanto ao grau de comunicação e interatividade, possibilitado pelo AVA, $76 \%$ dos respondentes consideram 'satisfatório, por disponibilizar diferentes recursos que permitem um excelente sistema de comunicação e interação entre ensinantes e aprendentes', $14 \%$ 'não satisfatório, pois as interfaces comunicacionais e de conteúdos estão mal distribuídas, dificultando a comunicação e interação' e 10\% responderam 'nunca acessei o AVA, pois acompanho todas as informações através do e-mail pessoal'.

No que tange o impacto e influência que esses recursos tecnológicos têm exercido sobre o processo de ensino-aprendizagem, Maia e Mattar (2007, p. 68) afirmam que:

Sem dúvida, as novas mídias interativas resgataram a educação a distância no Brasil. [...] A EaD, agora com uma roupagem pós-moderna, cercada de interatividade por todos os lados, ressurgiu como a 'salvação' para todos os problemas educacionais e sociais [...], meio de democratizar o acesso à informação e ao conhecimento e forma de capacitação de um grande contingente da população brasileira que necessitava de um curso de graduação".

Por fim, perguntou-se aos estudantes da UNIASSELVI, Polo Paulo Afonso-Ba, se eles já haviam utilizado o AVA de outra Instituição, constatando-se que a maioria (92\%) afirmou que 'não' e o menor percentual (8\%) encontrado já utilizaram a sala virtual das seguintes Instituições: FACINTER, FTC, SEBRAE, SENASP, UNITINS e UNOPAR. As respostas demonstram que, para a maioria dos alunos (92\%), as possibilidades para a construção do próprio conhecimento, por meio do AVA, ainda são consideradas uma novidade.

É relevante salientar que $100 \%$ dos questionários foram entregues com as 3 (três) questões subjetivas 'sem respostas', porém, percebe-se que os aprendentes responderam com bastante pressa devido a reduzida carga horária dos encontros presenciais (aulas uma vez por semana) - o que representa um ponto negativo do instrumento de coleta de dados utilizado. Em suma, este fator não subtrai a importância dos principais achados do estudo.

\section{CONSIDERACÕ̃ES FINAIS}

Como foi possível vislumbrar, perante os dados coletados, conclui-se que o Ambiente Virtual de Aprendizagem é uma importante plataforma de suporte ao estudante de Educação a Distância, por exercer uma influência positiva no processo de ensino e aprendizagem.

Diante desses fatos, através do sistema bimodal da UNIASSELVI - parte presencial e parte a distância, ficou evidenciado um grau de interação e satisfação entre aluno e tecnologia. Assim, verifica-se que, apesar desta sala de aula virtual oferecer diferentes interfaces de informação, comunicação e de conteúdo - que auxiliam na promoção de uma aprendizagem contínua, significativa e autônoma; as respostas dos aprendentes demonstram o quão fundamental é a mediação pedagógica por parte do professor-tutor no transcorrer do curso.

Em consonância com essa evolução no modo de ensinar e aprender constata-se que os momentos assíncronos precisam ser mais frequentes neste ambiente educativo virtual, onde o estudante é agente na construção de novos saberes. Em função disso, a pesquisa realizada revelou informações relevantes e contribuiu para que os estudos fossem alcançados. No entanto, como sugestão para estudos futuros se pode 
realizar estudo sobre o índice de extraterritorialidade (alunos fora do Estado-sede) e evasão, uma vez que, o Polo UNIASSELVI, em Paulo Afonso-Ba, abrange os estados de Alagoas, Bahia, Pernambuco e Sergipe.

\section{REFERÊNCIAS}

CIEGLINSKI, Amanda. Alunos entendem mais de computador e internet do que professores. 2011. Disponível em: <http://agenciabrasil.ebc.com.br/noticia/2011-08-09/alunos-entendem-mais-de-computador-e-internet-do-que-professores-mostra-pesquisa>. Acesso em: 25 jun. 2012.

GONZALES, Mathias. Fundamentos da Tutoria em Educação a Distância. São Paulo: Avercamp, 2005.

HOLANDA, Juliana. Como será a educação a distância nos próximos anos. Ensino Superior, São Paulo: ano 10, n. 125, p. 22-25, fev. 2009.

KENSKI, V. Tecnologias e Ensino Presencial e a Distância. Campinas, SP: Papirus, 2003.

LAKATOS, Eva Maria; MARCONI, Marina de Andrade. Fundamentos de metodologia científica. 4 ed. rev. e ampl. São Paulo: Atlas, 2001.

LEI DE DIRETRIZES E BASES DA EDUCAÇÃO NACIONAL, Lei $\mathbf{n}^{\circ} \mathbf{9 . 3 9 4 / 9 6}$ de 20 de dezembro de 1996.

MAIA, Carmem; MATTAR, João. ABC da EaD: A educação a distância hoje. São Paulo: Pearson Prentice Hall, 2007.

MOORE, Michael; KEARSLEY, Greg. Educação a Distância: Uma Visão Integrada. São Paulo: Cengage Learning, 2008.

PALLOFF, R. M.; PRATT, K. $\mathbf{O}$ aluno virtual: um guia para trabalhar com estudantes on-line. Porto Alegre: Artmed, 2004.

PEREIRA, A. T. C.; SCHMITT, V.; DIAS, M. R. A C. Ambientes Virtuais de Aprendizagem. In: PEREIRA, Alice T. Cybis. (orgs). AVA - Ambientes Virtuais de Aprendizagem em Diferentes Contextos. Rio de Janeiro: Ciência Moderna Ltda., 2007.

SANCHEZ, Fábio. Anuário Brasileiro Estatístico de Educação Aberta e a Distância. 4 ed. São Paulo: Instituto Monitor, 2008. 
TAFNER, Elisabeth Penzlien; TOMELIN, Janes Fidélis; SIEGEL, Norberto. Educação a distância e métodos de autoaprendizado. Indaial: Grupo UNIASSELVI, 2009. anndrealves@hotmail.com 